Vol. 11 (2002): 245-251.

\author{
Research Note
}

\title{
Effect of arbuscular mycorrhizal fungi and pesticides on Cynara cardunculus growth
}

\author{
Miguel Marin, Manuel Ybarra, Ana Fé and Lorenzo García-Férriz \\ Comercial Técnica y Viveros, S. A., Departamento de I+D, Apartado 92, E-46250 L'Alcúdia, Valencia, Spain, \\ e-mail: laboratorio@cotevisa.com
}

\begin{abstract}
Wild cardoon (Cynara cardunculus L.) is a promising crop for biomass production. A nursery trial was conducted to investigate the effectiveness of mycorrhizal inoculation on the biomass yield of wild cardoon seedlings and the effect of the pesticides fosetyl-Al, folpet and propamocarb, as fungicides, and isofenphos, phoxim and oxamyl, as insecticides, on cardoon plant growth and the mycorrhization. The arbuscular mycorrhizal (AM) fungi inocula were: commercial inoculum with Glomus mosseae spores, and an inoculum of a Glomus sp. strain (AMF-i) isolated locally. Mycorrhizal inoculation with either inoculum increased cardoon shoot biomass compared to non-inoculated control plants. The pesticide applications had a neutral or positive effect on cardoon seedling growth. However, the AM fungi colonisation did not decrease except for plants colonised by G. mosseae and treated with the insecticides isofenphos and oxamyl. Thus, the mycorrhiza can survive to pesticide concentrations employed in commercial nursery, and enhance cardoon plant productivity.
\end{abstract}

Key words: mycorrhizas, fungicides, insecticides, nurseries

\section{Introduction}

Cynara cardunculus L., wild cardoon, is widely distributed in central and western Mediterranean areas, and has been traditionally used for forage (Ryder et al. 1983). Recently, interest in this plant has increased due to potential industrial applications of some of the plant constituents as proteases in cheesemaking (Costa et al. 1996) and antibiotic production (Grancai et al. 1994), or as a bioenergetic source (Fernández et al. 1997). Wild cardoon is adapted to continental
Spanish climatology, and can be used to protect soils from degradation, at the some time as producing a valuable crop.

Mycorrhiza, symbiotic associations between plant roots and determined soil fungi, play a key role in mineral cycling in the ecosystem, affect nutrient uptake by plants, and have been shown to protect plants against biotic and abiotic stress factors (Azcón-Aguilar and Barea 1997), including pathogens (Azcón-Aguilar and Barea 1996). Most plant species are able to form mycorrhiza and the arbuscular type formed by zygomecetous fungi of the Glomalean order is the 
Marin, M. et al. AM fungi and pesticides upon Cynara cardunculus

most frequently found in vegetable crops (Barea et al. 1993). Different species or isolates of arbuscular mycorrhizal (AM) fungi have been shown to be more effective than others in promoting host plant growth (Abbott and Robson 1981, Bethlenfalvay et al. 1989). Different responses in the plants might be due to the interaction of the inoculated fungus with other soil microbiota and to the negative effects of pesticides and other agricultural practices in the establishment and development of the symbiosis (Schreiner and Bethlenfalvay 1996, Pattinson et al. 1997). The origin of the inocula and its efficacy under tested conditions are factors that need to be considered in large-scale artificial inoculation.

In a nursery, the use of pesticides is a common practice to prevent infections by phytopathogenic agents. However these pesticides might have an effect on the mycorrhizal association (Trappe et al. 1984). Therefore, prior to the commercial use of AM fungi in a nursery, the effect of commonly used pesticides on the AM symbiosis needs to be evaluated. Fosetyl-Al is a frequently used systemic fungicide and its effect on AM fungi colonisation and the host plant have been reported with contradicting results. Applications of this fungicide have shown both a decrease (Sukarno et al. 1993, Seymour et al. 1994, Sukarno et al. 1996, 1998) and an increase (Jabaji-Hare and Kendrick 1987, Plenchette and Perrin 1992) of the root colonisation. Other common fungicides used in a nursery are propamocarb, a systemic pesticide that does not seem to affect the symbiosis (Fontanet et al. 1998), and folpet, a preventative fungicide that has been shown to delay the establishment of the symbiosis (Schüepp and Bodmer 1981). The effect of the insecticides, isofenphos, phoxim and oxamyl on mycorrhizal plants has not been studied before.

The aims of this research were: 1) to assess the influence of mycorrhizal colonisation on the growth of wild cardoon using two different AM fungi (commercial and native strains) as inoculum; 2) to investigate the influence of six pesticides, three fungicides and three insecticides, on AM fungi colonisation.

\section{Material and methods}

The experiment was carried out in nurseries of Comercial Técnica y Viveros, S.A. (COTEVISA), L'Alcúdia, Valencia, Spain. The experimental design was a randomised block including seven pesticide treatments: three fungicides (fosetyl$\mathrm{Al}$, folpet and propamocarb), three insecticide treatments (phoxim, oxamyl and isofenphos) and a control without pesticide applications. These were combined with three AM inoculation treatments: plants inoculated with a commercial inoculum, plants inoculated with a native isolate and non-inoculated plants.

The cardoon seeds were obtained from "Escuela de Ingenieros Agrónomos de la Universidad Complutense" (Madrid, Spain) and were sown in $60 \mathrm{ml}$ pots. The potting substrate was a mixture $1: 1(\mathrm{v} / \mathrm{v})$ of peat $(12 \mathrm{~N}: 14 \mathrm{P}: 18 \mathrm{~K}$; Pindstrup Moseburg S.A.E., Burgos, Spain) and coconut fibre (Cocopeat ${ }^{\circledR}$; Projar S.A., Valencia, Spain) plus $0.5 \mathrm{~g} \mathrm{l}^{-1}$ of a controlled-release fertilizer (Osmocote ${ }^{\circledR}$ Mini, 2-3 months, 18N:6P: 12K; Scotts Europe B.V., Heerlen, Netherlands). Additional fertilizers were not applied during the experiment. Before sowing, the cardoon seedlings were soaked in water overnight. Each mycorrhizal inoculum was mixed with the potting substrate to achieve an inoculum concentration of $5 \%(\mathrm{v} / \mathrm{v})$. Two types of AM fungus inoculum were used: a commercial inoculum (Endorize $\mathrm{M}$ from Biorize, Dijon, France) with Glomus mosseae (Nicol. \& Gerd.) Gerd. \& Trappe spores, and a native endophyte inoculum produced from an AM fungus (AMF-i) isolated from locally grown onion roots in L'Alcúdia (Valencia, Spain). AMF-i starter inoculum was handed over to Biorize to be cultivated and to produce sufficient quantity of inoculum. The AMF-i is a Glomus species that has not been identified yet.

The pesticides used were the fungicides fosetyl-Al (Aliette ${ }^{\circledR} 80 \mathrm{~W}$, Rhône Poulenc Agrochimie, France), folpet (Ortho Phaltan ${ }^{\circledR} 80 \mathrm{~W}$, Agrodán S.A., Madrid, Spain) and propamocarb (Previcur $^{\circledR}$ N, AgrEvo Ibérica S.A., Valencia, 
Vol. 11 (2002): 245-251.

Spain); and, as insecticides were isofenphos (Oftanol ${ }^{\circledR} 5 \mathrm{G}$, Bayer Hispania, Barcelona, Spain), phoxim (Volaton ${ }^{\circledR} 10 \mathrm{G}$, Bayer Hispania, Barcelona, Spain) and oxamyl (Vydate ${ }^{\circledR} 10 \mathrm{G}$ DuPont, E. I. Du Pont de Nemours \& Co., UK). Fosetyl-Al and folpet, formulated as wettable powders, and propamocarb, as an emulsifiable concentrate, were used as soil drenches on oneweek-old cardoon seedlings. The concentrations applied were comparable to those used in commercial nurseries and were, respectively, of 6, 4 and $8 \mathrm{mg}$ a.i. (active ingredient) $\mathrm{ml}^{-1}$ of water per plant. These fungicides are applied as preventive treatment and against a broad spectrum of fungal diseases in commercial nurseries. In the insecticide treatments, pots were filled with the substrate mixed previously with the insecticide to achieve a concentration of $5 \mathrm{mg}$ a.i. $\mathrm{l}^{-1}$ of substrate, corresponding to standard nursery applications. After overnight soaking cardoon seeds were sown in pots. These insecticides are applied to protect against larvae and nematodes from soil and have a broad spectrum of disease control.

The increase in growth of cardoon seedlings, measured as shoot dry weight (SDW), the root : shoot $(\mathrm{R}: \mathrm{S})$ ratio and the percentage mycorrhizal colonisation (\% AM) were measured after 8 weeks of seedling growth; twenty plants per treatment were used to measure the SDW and $\mathrm{R}$ : $\mathrm{S}$ ratio, and ten plant roots to determine AM percentage root colonisation. Cardoon roots were stained using trypan blue (Brundrett et al. 1994), and mycorrhizal infection levels were determined by a grid-line intersect technique (Giovannetti and Mosse 1980). SDW, R : S ratio and percentage of AM fungi root colonisation data were analysed using two-way analysis of variance (ANOVA). Mycorrhizal infection data were arcsin transformed prior to analysis. All data were analysed using the Statgraphics Plus (STSC 1996). Means were compared with Tuckey's HSD multiple range test at the $95 \%$ confidence level.

\section{Results}

\section{Mycorrhization}

After 8 weeks of growth, the cardoon seedlings inoculated with the two AM fungi had bigger SDW and lower R : S ratios than non-inoculated plants (Table 1). Roots of non-inoculated plants were not mycorrhizated. Mycorrhizal plants inoculated with AMF-i and with G. mosseae shown similar R : S ratio and percentage root colonisation. However, the SDW of inoculated with G. mosseae and non-mycorrhizated seedlings were not significantly different and lower than AMF-i inoculated plants.

\section{Pesticides}

The application of the systemic fungicides, fosetyl-Al and propamocarb, both on non-inoculated seedlings and on G. mosseae mycorrhizal seedlings produced an increase in SDW compared with plants without fungicides. Plants inoculated with AMF-i did not show any significant differences (Table 1). There were no significant differences in the $\mathrm{R}: \mathrm{S}$ ratio nor in the percentage root colonisation. In the folpet treatment, plants inoculated with AMF-i had a higher SDW than folpet treated of non-inoculated and G. mosseae inoculated plants. Also, in this treatment the root colonisation was higher in the AMF-i inoculated seedlings than G. mosseae inoculated plants and the control plants inoculated with AMF-i. The R : S ratios of folpet treated plants inoculated with both fungi were smaller than those of non-mycorrhizal cardoons treated with folpet.

In AMF-i inoculated seedlings treated with isofenphos, a significant increase of SDW was observed compared with non-inoculated and non-treated plants (Table 1). Also, there was a significant reduction of the $\mathrm{R}: \mathrm{S}$ ratio, compared with plants treated with the same insecticide, either inoculated with G. mosseae or non-inoculated. The isofenphos application on G. mos- 


\section{Marin, M. et al. AM fungi and pesticides upon Cynara cardunculus}

Table 1. Means of shoot dry weight (SDW), root : shoot weight ratio (R:S) and mycorrhizal colonisation percentage (\% AM) of Cynara cardunculus L. plants inoculated with Glomus mosseae (Gm) spores, an AM fungus isolate (AMF-i) spores or non-inoculated control (Nil). Three fungicides were watered on one-week-old seedlings; three insecticides were mixed with substrate seeds; and one control without pesticide treatments. After 8 weeks of culture, cardoon plants were harvested.

\begin{tabular}{|c|c|c|c|c|c|c|c|c|c|}
\hline & \multicolumn{3}{|c|}{ SDW, g } & \multicolumn{3}{|c|}{$\mathrm{R}: \mathrm{S}$} & \multicolumn{3}{|c|}{$\% \mathrm{AM}$} \\
\hline & Nil & $\mathrm{Gm}$ & AMF-i & Nil & $\mathrm{Gm}$ & AMF-i & Nil & $\mathrm{Gm}$ & AMF-i \\
\hline Control & 0.49 & 0.74 & $0.95^{\mathrm{b}}$ & 1.12 & $0.50^{\mathrm{b}}$ & $0.54^{\mathrm{b}}$ & - & 70 & 69 \\
\hline \multicolumn{10}{|l|}{ Fungicides } \\
\hline Folpet & 1.05 & 0.74 & $2.00^{\mathrm{abc}}$ & 1.03 & $0.73^{b}$ & $0.88^{b}$ & - & 57 & $93^{\mathrm{ac}}$ \\
\hline Fosetyl-Al & $2.08^{\mathrm{a}}$ & $1.37^{\mathrm{a}}$ & 0.97 & 0.60 & 0.99 & 0.77 & - & 61 & 58 \\
\hline Propamocarb & $1.77^{\mathrm{a}}$ & $1.32^{\mathrm{a}}$ & 1.09 & 0.88 & 0.82 & 0.94 & - & 71 & 60 \\
\hline \multicolumn{10}{|l|}{ Insecticides } \\
\hline Isofenphos & 0.71 & 1.13 & $1.15^{\mathrm{a}}$ & 1.30 & 1.25 & $0.35^{\mathrm{bc}}$ & - & $24^{\mathrm{a}}$ & $96^{\mathrm{ac}}$ \\
\hline Oxamyl & 0.55 & 0.61 & 0.75 & 1.20 & 1.31 & $0.85^{\mathrm{bc}}$ & - & $50^{\mathrm{a}}$ & 78 \\
\hline Phoxim & 0.50 & 0.70 & $1.14^{\mathrm{b}}$ & 1.01 & 1.00 & 0.94 & - & 65 & 64 \\
\hline
\end{tabular}

a Significantly different $(\mathrm{P}<0.05)$ to control treatment in the same column.

b Significantly different $(\mathrm{P}<0.05)$ to non-AM inoculation in the same line.

${ }^{c}$ Significantly different $(\mathrm{P}<0.05)$ of AMF-i inoculations in relation to Glomus mosseae inoculations in the same line.

seae mycorrhizal plants produced a drastic reduction of the percentage AM root colonisation. However, the same insecticide had the opposite effect on the AMF-i inoculated cardoon plants where there was an increase in the AM root colonisation. Oxamyl also reduced G. mosseae root colonisation except to AMF-i inoculations that were not different from the colonisation observed in the non-pesticide treated plants. The other insecticide assayed, phoxim, increased significantly the SDW of AMF-i inoculated plants, but other parameters were unaffected.

The interactions between the pesticide (fungicide and insecticide) treatments and the AM fungi are shown in Table 2. The inoculation with the AM fungi alone did not modify cardoon SDWs in any case, even though they affected significantly the $\mathrm{R}: \mathrm{S}$ ratios and the mycorrhizal colonisation percentages. The fungicides did not affect significantly $\mathrm{R}$ : $\mathrm{S}$ ratio of seedlings and the insecticides the mycorrhizal colonisation percentage. The interaction among the insecticide and fungicides treatments and the AM fungi was significant, when assessing the SDW (except in insecticide treatments), the $\mathrm{R}: \mathrm{S}$ ratio and the AM root colonisation. Therefore the pesticides studied had a different effect related with the fungal isolate used for the inoculation.

\section{Discussion}

The results show that the mycorrhization in cardoon seedlings inoculated with both AM fungi increased the biomass (SDW) respect to the control plants. So, as described by Gianinazzi et al. (1990), lower R : S ratios in mycorrhizal plants have been associated with an effective symbiosis that allows an allocation of resources to the shoots. Our results indicate that mycorrhizal cardoon plants had a lower $\mathrm{R}: \mathrm{S}$ ratio than nonmycorrhizal plants. The application of mycorrhizal inoculations as other species of the cardoon family such as the artichoke (Cynara scolymus) should be evaluated in view of our results to assess its effects on commercial production.

The mycorrhizal cardoon seedlings of both AM fungi showed significant differences in 
Vol. 11 (2002): 245-251.

Table 2. $P$ values from ANOVA of the mycorrhizal and pesticides treatments for shoot dry weight (SDW), root : shoot weight ratio (R : S) and mycorrhizal colonisation percentage (\% AM) of Cynara cardunculus L. plants.

\begin{tabular}{llll}
\hline & SDW & R : S & \% AM \\
\hline Fungicides & & & 0.0185 \\
AM fungi & 0.2857 & 0.0130 & 0.0411 \\
Fungicides & 0.0071 & 0.4835 & 0.0000 \\
AM fungi $\times$ Fungicides & 0.0012 & 0.0001 & \\
Insecticides & & & 0.0919 \\
AM fungi & 0.4118 & 0.0063 & 0.9748 \\
Insecticides & 0.0009 & 0.0206 & 0.0000 \\
AM fungi $\times$ Insecticides & 0.1529 & 0.0000 & 0.0000 \\
Pesticides & & & 0.0109 \\
AM fungi & & 0.0020 & 0.0000 \\
Pesticides & 0.2043 & 0.0000 & 0.0000 \\
AM fungi $\times$ Pesticides & 0.0000 & & \\
\hline
\end{tabular}

a Pesticides is both fungicide and insecticide treatments.

SDW, though both reduced the $\mathrm{R}$ : $\mathrm{S}$ ratios compared to control plants. Previous studies suggest that there are many factors associated to the effectiveness in stimulating plant growth of different AM fungi (Barea et al. 1993), and the importance of physiological and genetic adaptation of AM fungi to environmental conditions (Azcón-Aguilar and Barea 1996). In this study there were growth differences between inoculated plants with each mycorrhizal fungus, but with our results, it is difficult to determine in field which will be better to produce high cardoon biomass and new works must be achieve.

The application of the pesticides, fungicides and insecticides, on cardoon seedlings increased the SDW yield. This increase was greater in the case of fungicides than in the case of insecticides treatments. The pesticide treatments had a significant effect on the cardoon growth that might be explained owing to the supply of resources to AM fungus in the roots together with the negative effect of pathogens cause stresses to the plants (Waters and Borowicz 1994), but the pesticides aid to control plant decays. Thus, this phenomenon can enhancing plant growth, as Pattinson et al. (1997) observed after treated mycorrhizated cotton seedlings with different pesticides.
The G. mosseae inoculated seedlings treated with the fungicides fosetyl-Al and propamocarb might have increased the SDW yield compared to the control treatment by the inhibitory action on the fungal pathogens. The effective symbiosis between plant-fungus did not happen in spite of the presence of the mycorrhizal roots because the $\mathrm{R}: \mathrm{S}$ ratios among treatments were similar. However, on AMF-i inoculated seedlings there was no significant effect on SDW yield nor on $\mathrm{R}: \mathrm{S}$ ratio under the same conditions. Probably, the cardoon seedlings allocated resources to AM fungus, but because of the negative effect of the pesticides on the AM fungus, the plants did not benefit from the mycorrhizal symbiosis. The folpet treatment did not inhibit effective symbiosis of both mycorrhizal fungi, here the $\mathrm{R}: \mathrm{S}$ ratios were reduced. The results between fungi were different with this fungicide: AMF-i inoculated seedlings increased the SDW yield and the mycorrhizal root colonisation was stimulated; these effects did not happen with G. mosseae seedlings. Thus, folpet promoted cardoon growth and AMF-i fungus colonisation for a positive balance of the mycorrhizal symbiosis. Jabaji-Hare and Kendrick (1987) already described different effects of fungicides on mycorrhizal symbiosis, and in the same experiment, they ob- 
Marin, M. et al. AM fungi and pesticides upon Cynara cardunculus

served that the fungicide metalaxyl reduced the growth of leek mycorrhizal plants, but fosetyl$\mathrm{Al}$ increased growth plant when the concentration of fungicide was increased.

The application of insecticides did not produce meaningful increases in the SDW of the treated seedlings. Probably, the insects had a lower harmful effect on cardoon seedlings. However, the insecticides affected each mycorrhizal inoculation in a different way. Mycorrhizal root colonisations of G. mosseae were decreased with isofenphos and oxamyl; an effective symbiosis did not happen. However, the same insecticides increased root colonisations and decreased $\mathrm{R}$ : $\mathrm{S}$ ratio in AMF-i inoculations; insecticides had positive effect on this fungus and its mycorrhization, mainly isofenphos. The AM fungi react differently to the pesticides (Schreiner and Bethlenfalvay 1996, Pattinson et al. 1997), and the research should be developed towards the discovery of chemical forms compatible with the endomycorrhizal fungi employed in each situation.

In conclusion, the beneficial effects of the mycorrhization of wild cardoon on biomass have been observed at nursery level. The majority of pesticides annulled the effect of the mycorrhizal symbiosis, but due to phytopathogens hinder the cardoon growth, mainly in this case for fungal decays, the application of fungicides is made necessary. At least, in our study most of the pesticides treatments do not prevent a normal infectiveness of AM fungi inocula, and except G. mosseae with insecticides isofenphos and oxamyl, the percentage of mycorrhizated roots in presence of pesticides was not decreased. It is important to achieve a good mycorrhizal root colonisation because these seedlings will be sown in field locations where the number of native inocula is very low because of topsoil erosion. Therefore, it must be expected that when the plants are transplanted into the field, and disappear the remains from the pesticides, the beneficial effects of mycorrhizal symbiosis will be showed in cardoon plants.

Acknowledgements. We thank Professor J. Fernández, from "Escuela de Ingenieros Agrónomos de la Universidad Complutense" (Madrid, Spain), for giving us the cardoon seeds. These investigations were in part supported by the project EUREKA EU2134-MYCORA and by the company Comercial Técnica y Viveros, S.A. 
Vol. 11 (2002): 245-251.

\section{References}

Abbott, L.K. \& Robson, A.D. 1981. Infectivity and effectiveness of five endomycorrhizal fungi: Competition with indigenous fungi in field soils. Australian Journal of Agricultural Research 32: 621-630.

Azcón-Aguilar, C. \& Barea, J.M. 1996. Arbuscular mycorrhizas and biological control of soil-borne plant pathogens - an overview of the mechanisms involved. Mycorrhiza 6: 457-464.

Azcón-Aguilar, C. \& Barea, J.M. 1997. Applying mycorrhiza biotechnology to horticulture: significance and potentials. Scientia Horticulturae 68: 1-24.

Barea, J.M., Azcón, R. \& Azcón-Aguilar, C. 1993. Mycorrhiza and crops. In: Tommerup, I. (ed.). Advances in plant pathology. Vol. 9. Mycorrhiza: A synthesis. London: Academic Press. p. 167-189.

Bethlenfalvay, G.J., Franson, R.L., Dakessian, S., Brown, M.S. \& Mihara, K.L. 1989. The Glycine-GlomusRhizobium symbiosis. IX. Nutritional, morphological, and physiological responses of nodulated soybean to geographic isolates of the mycorrhizal fungus Glomus mosseae. Physiological Plantarum 76: 226232.

Brundrett, M. 1994. Clearing and staining mycorrhizal roots. In: Brundrett, M. et al. (eds.). Practical methods in mycorrhiza research. Ontario: Mycologue Publications, University of Guelph. p. 42-46.

Costa, M.E.L., Van Gulik, W.N., Pais, M.S.S., Cabral, J.M.S., Van Gulik, W.M. \& Ten Hoopen, H.J.G. 1996. Protease and phenol production of Cynara cardunculus L. cell suspension in a chemostat. Enzyme and Microbiology Technology 19: 493-500.

Fernández, J., Marquez, L. \& Venturi, P. 1997. Technical and economic aspects of Cynara cardunculus L.: an energy crop for the Mediterranean region. Mediterranean 8: 48-51.

Fontanet, X., Estaun, V., Camprubi, A. \& Calvet, C. 1998. Fungicides added to potting substrate affect mycorrhizal symbiosis between a peach-almond rootstock and Glomus sp. HortScience 33: 1217-1219.

Gianinazzi, S., Trouvelot, A. \& Gianinazzi-Pearson, V. 1990. Role and use of mycorrhizas in horticultural crop production. XXIII International Horticulture Congress, Florence, Italy. p. 25-30.

Giovannetti, M. \& Mosse, B. 1980. An evaluation of techniques for measuring vesicular arbuscular mycorrhizal infection in roots. New Phytologist 84: 489-500.

Grancai, D., Nagy, M., Suchy, V. \& Novomesky, P. 1994. Cynarin from the fresh flower buds of Cynara cardunculus. Fitoterapia 65: 282.

Jabaji-Hare, S.H. \& Kendrick, W.B. 1987. Response of an endomycorrhizal fungus in Allium porrum L. to different concentrations of the systematic fungicides, metalaxyl (Ridomil $\left.{ }^{\circledR}\right)$ and fosetyl-Al $\left(\right.$ Aliette $\left.^{\circledR}\right)$. Soil Biology and Biochemistry 19: 95-99.

Pattinson, G.S., Warton, D.I., Misman, R. \& McGee, P.A. 1997. The fungicides Terrazole and Terraclor and the nematicide Fenamiphos and growth of cotton seedlings. Mycorrhiza 7: 155-159.

Plenchette, C. \& Perrin, R. 1992. Evaluation in the greenhouse of the effects of fungicides on the development of mycorrhiza on leek and wheat. Mycorrhiza 1: $59-62$.

Ryder, J.E., De Vos, N.E. \& Bari, M.A. 1983. The globe artichoke (Cynara scolymus L.) HortScience 18: 646652.

Schüepp, H. \& Bodmer, M. 1981. Effect of selected fungicides on vesicular-arbuscular mycorrhizal infection in field trials. $5^{\text {th }}$ North American Conference of Mycorrhizae, Quebec, Canada. p. 70.

Seymour, N.P., Thompson, J.P. \& Fiske, M.L. 1994. Phytotoxicity of fosetyl Al and phosphonic acid to maize during production of vesicular-arbuscular mycorrhizal inoculum. Plant Disease 78: 441-446.

Schreiner, R.P. \& Bethlenfalvay, G.J. 1996. Mycorrhizae biocides and biocontrol. 4. Response of a mixed culture of arbuscular mycorrhizal fungi and hosts plant to three fungicides. Biology and Fertility Soils 23: 189-195.

STSC 1996. Statgraphics plus for Windows 2.1. STSC Inc. Rockville, MD.

Sukarno, N., Smith, S.E. \& Scott, E.S. 1993. The effect of fungicides on vesicular-arbuscular mycorrhizal symbiosis: I. The effects on vesicular-arbuscular mycorrhizal fungi and plant growth. New Phytologist 125: 139-147.

Sukarno, N., Smith, S.E. \& Scott, E.S. 1996. The effect of fungicides on vesicular-arbuscular mycorrhizal symbiosis. II. The effects on area of interface and efficiency of $\mathrm{P}$ uptake and transfer to plant. New Phytologist 132: 583-592.

Sukarno, N., Smith, F.A., Scott, E.S., Jones, G.P. \& Smith, E.S. 1998. The effect of fungicides on vesicular-arbuscular mycorrhizal symbiosis III. The influence of VA mycorrhiza on phytotoxic effects following-application of fosetyl-Al and phosphonate. New Phytologist 139: 321-330.

Trappe, J.M., Molina, R. \& Castellano, M. 1984. Reactions of mycorrhizal fungi and mycorrhiza formation to pesticides. Annual Review of Phytopathology 22: 331-359.

Waters, J.R. \& Borowicz, V.A. 1994. Effect of clipping, benomyl, and genet on ${ }^{14} \mathrm{C}$ transfer between mycorrhizal plants. Oikos 71: 246-252. 